\title{
Clinical Characteristics and In-Hospital Outcome of Acute Heart Failure Patients Admitted to the Medical Ward of University of Gondar Comprehensive Specialized Hospital, Northwest Ethiopia
}

\author{
Masho Tigabe (iD)' \\ Abaynesh Fentahun' \\ Solomon Getawa (iD) ${ }^{2}$ \\ Kassahun Alemu Gelaye (iD ${ }^{3}$ \\ Eyob Alemayehu Gebreyohannes (ID) \\ 'Department of Clinical Pharmacy, \\ School of Pharmacy, College of Medicine \\ and Health Sciences, University of \\ Gondar, Gondar, Ethiopia; ${ }^{2}$ Department \\ of Hematology and Immunohematology, \\ School of Biomedical and Laboratory \\ Sciences, College of Medicine and Health \\ Sciences, University of Gondar, Gondar, \\ Ethiopia; ${ }^{3}$ Department of Epidemiology \\ and Biostatistics, Institute of Public \\ Health, College of Medicine and Health \\ Sciences, University of Gondar, Gondar, \\ Ethiopia; ${ }^{4}$ Division of Pharmacy, School of \\ Allied Health, University of Western \\ Australia, Nedlands, Australia
}

Background: Despite the growing burden of heart failure in developing countries, data describing the clinical characteristics and in-hospital outcomes of acute heart failures are limited. Therefore, this study aimed at describing the clinical characteristics and in-hospital outcomes of acute heart failure patients admitted to the medical ward of University of Gondar Comprehensive Specialized Hospital, Northwest Ethiopia.

Methods: A prospective observational hospital-based cross-sectional study was conducted on 226 patients with acute heart failure at the University of Gondar Comprehensive Specialized Hospital from November 2019 to October 2020. Data were collected by using a pretested data abstraction format and analyzed with Statistical Package for Social Sciences version 21. Bivariable and multivariable binary logistic regression model were fitted to identify factors associated with in-hospital outcome and reported with $95 \%$ confidence interval (CI). P-value $<0.05$ was considered as statistically significant.

Results: The mean ( \pm standard deviation) age of the study participant was $51.17 \pm 19.03$ years and $59.3 \%$ were females. Majority, $60.6 \%$ of patients were admitted with new onset heart failure. Dyspnea (88.05\%) and peripheral edema $(80.5 \%)$ were the most frequent clinical findings. The in-hospital mortality was $10.6 \%$ (95\% CI: 7.1-14.7). Atrial fibrillation $(\mathrm{AOR}=9.46 ; 95 \% \mathrm{CI}: 1.49-60.29)$, concurrent ischemic heart disease (AOR $=8.23 ; 95 \% \mathrm{CI}$ : 1.15-58.89), being admitted with reduced left ventricular ejection fraction ( $\mathrm{AOR}=5.36 ; 95 \%$ CI: 2.81-35.52), presence of orthopnea ( $\mathrm{AOR}=6.63 ; 95 \% \mathrm{CI}: 2.94-46.76$ ), and using intranasal oxygen therapy (AOR=9.41;95\% CI: 1.35-65.82) were significantly associated with in-hospital mortality in patients with acute heart failure.

Conclusion: The in-hospital mortality of acute heart failure patients was relatively higher in the study area. Therefore, specific preventative and therapeutic strategies focusing on heart failure patients with reduced left ventricular ejection fraction, atrial fibrillation, ischemic heart disease, orthopnea, and intranasal oxygen therapy are required to reduce the mortality rate.

Keywords: heart failure, clinical characteristics, in-hospital mortality, Ethiopia

\section{Introduction}

Acute Heart Failure (AHF) is defined as the rapid development or change of signs and symptoms of heart failure (HF) that requires urgent medical intervention. ${ }^{1}$ On admission, patients with AHF may experience numerous signs and symptoms 
Table I Socio-Demographic and Clinical Characteristics of AHF Patients Admitted to the Medical Ward of University of Gondar Comprehensive Specialized Hospital from 2019 to 2020

\begin{tabular}{|c|c|c|c|c|}
\hline Variable & Categories & Frequency (\%) & Mean \pm SD & Median (IQR) \\
\hline Age (years) & & & $51.17 \pm 19.03$ & \\
\hline Gender & $\begin{array}{l}\text { Male } \\
\text { Female }\end{array}$ & $\begin{array}{l}92(40.7) \\
134(59.3)\end{array}$ & & \\
\hline Precipitating factors & $\begin{array}{l}\text { Undefined } \\
\text { AF } \\
\text { Non-compliance } \\
\text { Infection (CAP) }\end{array}$ & $\begin{array}{l}71(31.4) \\
34(15.0) \\
38(16.8) \\
83(36.7)\end{array}$ & & \\
\hline Comorbidities & $\begin{array}{l}\text { CAP } \\
\text { IHD } \\
\text { DVHD } \\
\text { HTN } \\
\text { AF } \\
\text { Anemia } \\
\text { CRHD } \\
\text { Renal disease } \\
\text { AF } \\
\text { DM }\end{array}$ & $\begin{array}{l}112(49.6) \\
66(29.2) \\
62(27.4) \\
60(26.5) \\
59(26.1) \\
58(25.7) \\
43(19.0) \\
43(19.0) \\
59(26.1) \\
11(4.9)\end{array}$ & & \\
\hline Causes of AHF & $\begin{array}{l}\text { IHD } \\
\text { HHD } \\
\text { CRHD } \\
\text { Corpulmonale } \\
\text { DCM } \\
\text { DVHD } \\
\text { Anemia } \\
\text { Others }\end{array}$ & $\begin{array}{l}61(27.0) \\
10(4.4) \\
44(19.5) \\
40(17.7) \\
31(13.7) \\
20(8.8) \\
9(4.0) \\
11(4.9)\end{array}$ & & \\
\hline NYHA classification & $\begin{array}{l}\text { III } \\
\text { IV }\end{array}$ & $\begin{array}{l}5(2.2) \\
221(97.8)\end{array}$ & & \\
\hline Vital signs & $\begin{array}{l}\text { Systolic blood pressure }(\mathrm{mmHg}) \\
\text { Diastolic blood pressure }(\mathrm{mmHg}) \\
\text { Heart rate (beats/minute) } \\
\text { Respiratory rate (breaths/minute) } \\
\text { Temperature }\left(\mathrm{C}^{0}\right)\end{array}$ & & & $\begin{array}{l}110(100-120) \\
70(60-80) \\
96(88-110) \\
24(22-28) \\
36.5(36.2-36.9)\end{array}$ \\
\hline Laboratory findings & $\begin{array}{l}\text { Serum creatinine }(\mathrm{mg} / \mathrm{dl}) \\
\text { Serum sodium }(\mathrm{meq} / \mathrm{L}) \\
\text { Serum potassium }(\mathrm{meq} / \mathrm{L}) \\
\text { Hemoglobin }(\mathrm{g} / \mathrm{dl})\end{array}$ & & $\begin{array}{l}139.19 \pm 5.64 \\
3.95 \pm 0.80 \\
12.04 \pm 3.28\end{array}$ & $0.88(0.7 I-I .30)$ \\
\hline
\end{tabular}

Abbreviations: IHD, ischemic heart disease; CRHD, chronic rheumatic heart disease; DCMP, dilated cardiomyopathy; DVHD, degenerative valvular heart disease; HHD, hypertensive heart diseases; CAP, community-acquired pneumonia; HTN, hypertension; AF, atrial fibrillation; NYHA, New York Heart Association; SD, standard deviation; $\mathrm{IQR}$, interquartile range.

including dyspnea, paroxysmal nocturnal dyspnea, elevated jugular venous pressure, peripheral edema, murmur, $\mathrm{S}_{3}$ gallop, orthopnea, neck vein distension, and easy fatigability. ${ }^{2}$ Cardiac conditions such as uncontrolled hypertension (HTN), arrhythmias, as well as non-cardiac situations such as diabetes mellitus, renal dysfunction, infection, and non-adherence to medical regimen are major precipitants that may lead to decompensation and hospital admissions. ${ }^{3-11}$ Infection, arrhythmia, anemia, myocardial infarction, and drug discontinuation are the 


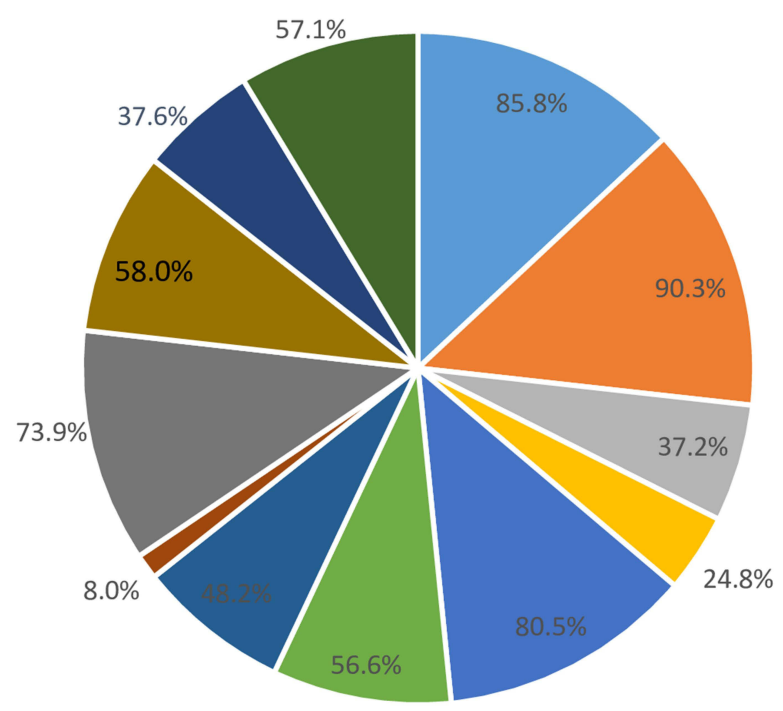

$\begin{array}{lll}\text { - Dyspnea at rest } & \text { - Dyspnea on exertions } & \text { - Easy fatiguablity } \\ \text { - Atrial fibrillation } & \text { - Peripheral edema } & \text { - Elevated jugular venous pressure } \\ \text { - Cardiomegally } & \text { - S3 gallop } & \text { - Orthpnea } \\ \text { - Paroxymal nocturnal dyspnea } & \text { - Neck vein distension } & \text { - Murmur }\end{array}$

Figure I Clinical findings of AHF patients admitted to the medical ward of University of Gondar comprehensive specialized hospital from 2019 to 2020.

most frequent precipitant factors for AHF admission in Ethiopia. ${ }^{12}$

Despite the recent advances in therapy for HF, several scientific literatures described that majority of hospitalized acute heart failure (HAHF) patients experience a high inhospital mortality rate with an estimated range of 6.3 24.4\%. ${ }^{7-10,13-19}$ A prospective cohort study in Brazil reported that the in-hospital mortality of HF patients was $21.6 \% .{ }^{20}$ A retrospective observational study in Cameroon reported that intra-hospital mortality was $18.45 \% .{ }^{19}$ In Ethiopia, the in-hospital mortality rate of hospitalized HF patients was $24.4 \%{ }^{14}$

In spite of the growing burden of HF in developing countries including Ethiopia, studies regarding the clinical characteristics and in-hospital outcomes of AHF among hospitalized patients are conducted mainly in the developed world. Thus, in the study area data regarding to clinical characteristics and in-hospital outcomes of AHF patients have not been well described. Therefore, the study was conducted with the aim of describing the clinical characteristics and in-hospital outcomes of HAHF patients admitted at the University of Gondar Comprehensive Specialized Hospital medical ward, Northwest Ethiopia.

\section{Methods and Materials Study Design, Setting and Period}

A prospective observational hospital-based cross-sectional study was conducted at the University of Gondar Comprehensive Specialized Hospital medical ward from November 2019 to October 2020. The hospital is located in the central Gondar zone, Gondar town, Amhara Regional State. It is located at $738 \mathrm{~km}$ far from the capital city of Ethiopia, Addis Ababa, and $180 \mathrm{~km}$ far from the capital city of the region, Bahir Dar. The town is situated at 2133 meters elevation above sea level. Currently, the hospital has four major departments wards namely pediatrics, internal medicine, surgery, gynecology and obstetrics. Each department has emergency, inpatient and outpatient units. The internal medicine inpatient has two main subunits, ward $\mathrm{C}$ (serves for female patients) and ward D (serves for male patients). HAHF patients are managed in either ward $\mathrm{C}$ or ward $\mathrm{D}$. The internal medicine wards mainly run by nurses, resident and interns under supervision of senior physicians.

\section{Source and Study Population}

All HAHF patients admitted at the University of Gondar Comprehensive Specialized Hospital medical ward were 
taken as the source population, whereas AHF patients who admitted at the University of Gondar Comprehensive Specialized Hospital medical ward during the study period and willing to participate in the study were considered as the study population.

\section{Eligibility Criteria}

All patients with a diagnosis of AHF aged 18 years and above admitted to the medical ward of the University of Gondar Comprehensive Specialized Hospital and underwent HF-specific treatment during hospitalization were included. However, AHF patients in the intensive care unit (ICU) were excluded from the study.

\section{Sample Size Determination and Sampling Technique}

A total of 242 patients with a diagnosis of AHF were attended the medical ward of the University of Gondar Comprehensive Specialized Hospital from November 2019 to October 2020. From those AHF patients, 226 of them who fulfill the inclusion criteria were included in this study. A convenience sampling technique was used to select study participants.

\section{Study Variables}

The in-hospital mortality of AHF patients was the primary outcome of this study. Besides, the socio-demographic variables (sex and age) and clinical characteristics such as causes of AHF (ischemic heart disease (IHD), HTN, atrial fibrillation (AF), stroke, dilated cardiomyopathy (DCMP), degenerative valvular heart disease (DVHD), chronic rheumatic heart disease (CRHD), corpulmonale, anemia, asthma, chronic obstructive pulmonary disease, thyroid disorder, and renal disease), precipitating factors of AHF (DCMP, AF, HTN, IHD, non-adherence to medical regimen, tuberculosis, community-acquired pneumonia (CAP), anemia, renal disease, and thyroid disorder), comorbidity (dyslipidemia, renal disease, cor pulmonale, diabetes mellitus, liver disease, stroke, thyroid disease, asthma, cancer, chronic obstructive pulmonary disease, tuberculosis, anemia, human immunodeficiency virus, IHD, HTN, AF, CRHD, DVHD, and CAP), clinical presentation at admission (New York Heart Association (NYHA) functional class, paroxysmal nocturnal dyspnea, AF, systolic blood pressure, diastolic blood pressure, heart rate, left ventricular ejection fraction (LVEF), serum creatinine, hemoglobin, serum sodium, serum potassium, dyspnea at rest, dyspnea on exertion, easy fatigability, peripheral edema, elevated jugular venous pressure, cardiomegaly, S3 gallop, orthopnea, neck vein distension, and murmur), medications, and mechanical ventilation usage were considered as independent variables.

\section{Data Collection Procedures}

Data were collected by using a pretested data abstraction format by three trained nurses. Data abstraction format was prepared by reviewing similar studies. ${ }^{4,11,13,14,17,18,21,22}$ Data regarding demographic variables, medical history, medication use, clinical presentation on admission, echocardiographic and laboratory findings, in-hospital treatment and outcomes were collected and recorded on the data abstraction format from admission until their discharge from the ward. Information on the clinical characteristics, management and in-hospital outcome of AHF patients were collected through medical chart review.

\section{Data Quality Control Technique}

To assure the completeness of the data abstraction format, a pre-test was conducted in the emergency in-patient ward, and proper modification was employed to the format.

\section{Operational Definitions}

In-hospital mortality: AHF patient died in the hospital after he/she was admitted to the medical ward; AHF: Development or change of signs and symptoms of new onset of $\mathrm{HF}$ and/or decompensation or worsening of chronic stable HF while New-onset HF: AHF which occurs in patients without a history of $\mathrm{HF}^{1}$

Acutely decompensated chronic heart failure (ADCHF): AHF which occurs in patients with a history of chronic HF while reduced ejection fraction and preserved ejection fraction: patients whose LVEF was $\leq 40 \%$ and $\geq 50 \%$, respectively based on echocardiographic finding. ${ }^{1}$

Ischemic heart disease: Heart problems caused by narrowed heart arteries that supply blood to the heart muscle, ${ }^{23}$ Non-compliance with medication: any form of deviation from compliance like losing one appointment, missing doses, etc. (instructions not understood, cost, not availability of drug), ${ }^{24}$ Rheumatic Heart disease (CRHD): long-term cardiac damage caused by either a single severe episode or multiple recurrent episodes of acute rheumatic fever, ${ }^{25}$ Anemia: altitude adjusted hemoglobin ( $\left.\mathrm{Hgb}\right)$ level $<13 \mathrm{~g} / \mathrm{dL}$ in men and $<12 \mathrm{~g} / \mathrm{dL}$ in women. ${ }^{26}$ 


\section{$120.0 \%$}

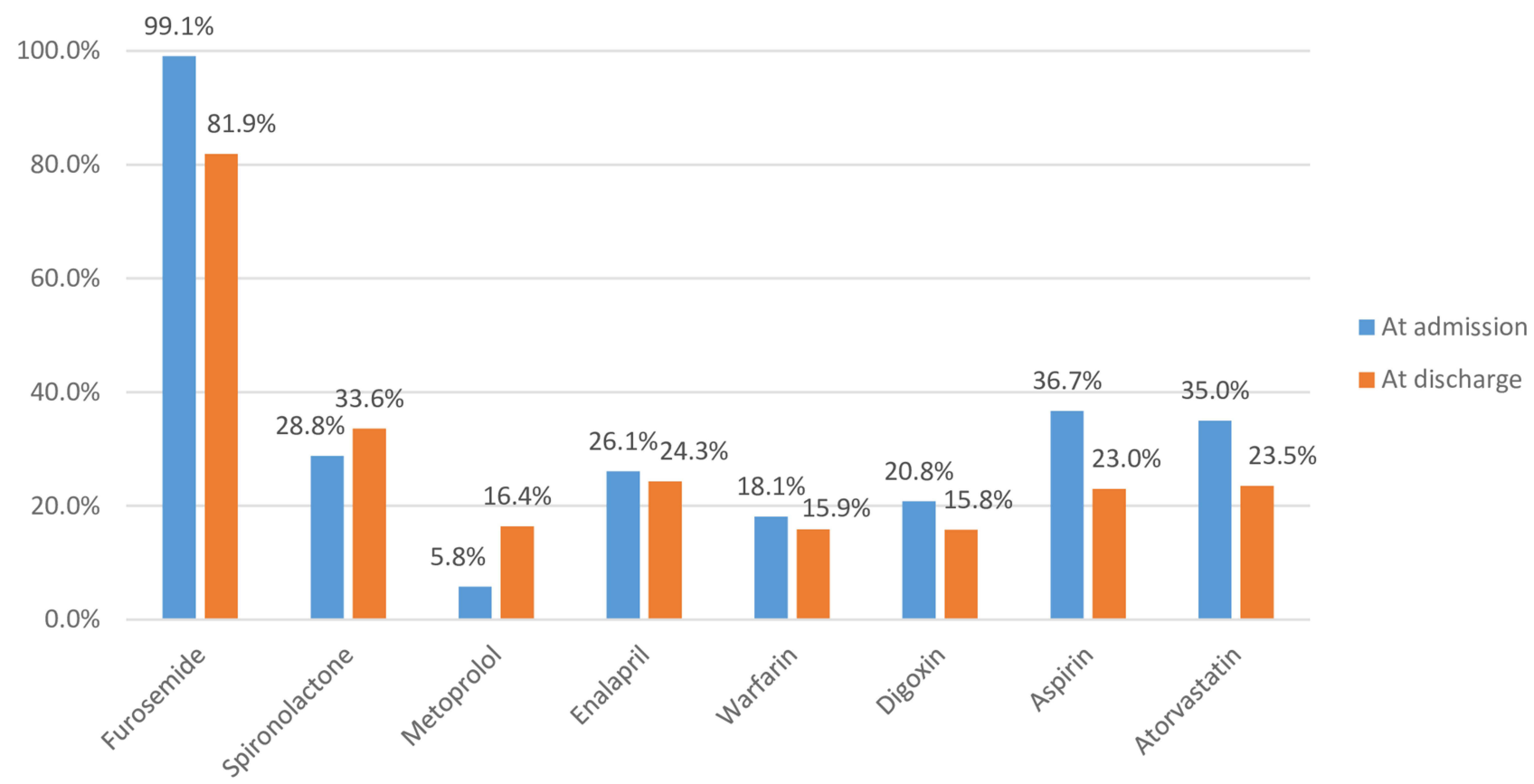

Figure 2 Medications received by AHF patients admitted to the medical ward of University of Gondar comprehensive specialized hospital from 2019 to 2020.

\section{Data Entry and Statistical Analysis}

Data was edited; cleaned, coded, entered, and analyzed using Statistical Package for Social Sciences (SPSS) version 21. Descriptive analysis was used to summarize the clinical characteristics, management and in-hospital outcomes of AHF patients. Continuous variables were expressed as mean $( \pm \mathrm{SD})$ when normally distributed or median (IQR) when not normally distributed. Additionally, categorical variables were summarized as frequency (percentage) of the total. Binary logistic regression was used to determine the associated factors of in-hospital mortality. The Hosmer-Lemeshow goodness-of-fit test was used to assess the fitness of the model. Both crude odds ratio (COR) and adjusted odds ratio (AOR) with the corresponding $95 \%$ confidence interval $(\mathrm{CI})$ were calculated to show the strength of association. $\mathrm{P}$ value $<0.05$ in the multivariable regression model was considered as statistically significant.

\section{Ethical Consideration}

Ethical clearance was obtained from the University of Gondar, College of Medicine and Health Sciences, School of Pharmacy, Research and Ethical Review Committee before data collection. Also, permission letter to conduct the study was obtained from the University of
Gondar Comprehensive Specialized Hospital Chief Executive clinical director. The objective of the research was explained orally and informed consent was obtained from the study participants. Then, those who were willing to participate were included in the study. Participation in the study was voluntary and refusal was possible. Furthermore, to ensure confidentiality, study participants were identified using codes, and only authorized persons accessed the collected data. This was approved by the ethical review committee.

\section{Results}

\section{Socio-Demographics and Clinical Characteristics of Patients}

A total of $242 \mathrm{HF}$ patients were admitted to the medical ward of the University of Gondar Comprehensive Specialized Hospital between November 2019 and October 2020. Of these, 226 patients were included in this study. Out of 226 study participants, $59.3 \%$ were females and mean age of the participants were $51.17 \pm$ 19.03 years. Among participants, 137 (60.6\%) of them were admitted with a diagnosis of new-onset HF, whereas the remaining $89(39.4 \%)$ of the patients were admitted with a diagnosis of ADCHF. 
Table 2 Bivariable and Multivariable Binary Logistic Regression Analysis of Explanatory Variables and In-Hospital Mortality of AHF Patients Admitted to the Medical Ward of University of Gondar Comprehensive Specialized Hospital from 2019 to 2020

\begin{tabular}{|c|c|c|c|c|c|}
\hline \multirow[t]{2}{*}{ Variable } & \multirow[t]{2}{*}{ Categories } & \multicolumn{2}{|c|}{ In-Hospital Mortality } & \multirow[t]{2}{*}{ COR $(95 \% \mathrm{Cl})$} & \multirow[t]{2}{*}{ AOR $(95 \% \mathrm{Cl})$} \\
\hline & & Yes $\mathbf{N}(\%)$ & No $\mathbf{N}(\%)$ & & \\
\hline Precipitating factors & $\begin{array}{l}\text { Undefined } \\
\text { Atrial fibrillation } \\
\text { Non-compliance to medical } \\
\text { CAP }\end{array}$ & $\begin{array}{l}2(2.8) \\
7(20.6) \\
9(23.7) \\
6(7.2)\end{array}$ & $\begin{array}{l}69(97.2) \\
27(79.4) \\
29(76.3) \\
77(92.8)\end{array}$ & $\begin{array}{l}0.37(0.07-1.9) \\
3.33(1.03-10.78) \\
3.98(1.30-12.18) \\
\operatorname{Ref}\end{array}$ & $\begin{array}{l}0.793(0.06-10.25) \\
9.46(1.49-60.29) * \\
0.16(0.01-3.72) \\
\operatorname{Ref}\end{array}$ \\
\hline HTN & $\begin{array}{l}\text { Yes } \\
\text { No }\end{array}$ & $\begin{array}{l}\text { I5 (25.0) } \\
9(5.4)\end{array}$ & $\begin{array}{l}45(75.0) \\
157(94.6)\end{array}$ & $\begin{array}{l}5.82(2.39-11.16) \\
\text { Ref }\end{array}$ & $\begin{array}{l}0.88(0.12-6.33) \\
\text { Ref }\end{array}$ \\
\hline Anemia & $\begin{array}{l}\text { Yes } \\
\text { No }\end{array}$ & $\begin{array}{l}9(15.5) \\
15(8.9)\end{array}$ & $\begin{array}{l}49(84.5) \\
153(81.9)\end{array}$ & $\begin{array}{l}\text { I.87 (0.78-4.54) } \\
\text { Ref }\end{array}$ & $\begin{array}{l}0.312(0.01-8.42) \\
\text { Ref }\end{array}$ \\
\hline Renal disease & $\begin{array}{l}\text { Yes } \\
\text { No }\end{array}$ & $\begin{array}{l}\text { II (25.6) } \\
\text { I3 (7.1) }\end{array}$ & $\begin{array}{l}32(74.4) \\
170(92.9)\end{array}$ & $\begin{array}{l}4.45(1.85-10.91) \\
\text { Ref }\end{array}$ & $\begin{array}{l}\text { I.54 (0.07-32.9I) } \\
\text { Ref }\end{array}$ \\
\hline Stroke & $\begin{array}{l}\text { Yes } \\
\text { No }\end{array}$ & $\begin{array}{l}3(37.5) \\
24(10.6)\end{array}$ & $\begin{array}{l}5(62.5) \\
202(89.4)\end{array}$ & $\begin{array}{l}5.63(1.26-25.23) \\
\text { Ref }\end{array}$ & $\begin{array}{l}2.63(0.11-65.03) \\
\operatorname{Ref}\end{array}$ \\
\hline IHD & $\begin{array}{l}\text { Yes } \\
\text { No }\end{array}$ & $\begin{array}{l}19(28.8) \\
5(3.1)\end{array}$ & $\begin{array}{l}47(7 \mid .2) \\
155(96.9)\end{array}$ & $\begin{array}{l}\text { I2.53(4.44-35.38) } \\
\text { Ref }\end{array}$ & $\begin{array}{l}8.23(1.15-58.89) * \\
\operatorname{Ref}\end{array}$ \\
\hline LVEF (\%) & $\begin{array}{l}\leq 40 \\
>40\end{array}$ & $\begin{array}{l}21(25.3) \\
3(2.1)\end{array}$ & $\begin{array}{l}62(74.7) \\
140(97.9)\end{array}$ & $\begin{array}{l}\text { I5.80(4.55-54.95) } \\
\text { Ref }\end{array}$ & $\begin{array}{l}5.36(2.8 I-35.52) * \\
\operatorname{Ref}\end{array}$ \\
\hline Serum Creatine (mg/dl) & $\begin{array}{l}\leq 1.2 \\
>1.2\end{array}$ & $\begin{array}{l}\text { II (6.6) } \\
\text { I3 (22.0) }\end{array}$ & $\begin{array}{l}156(93.4) \\
46(78.0)\end{array}$ & $\begin{array}{l}\text { Ref } \\
4.01(1.68-9.54)\end{array}$ & $\begin{array}{l}\text { Ref } \\
1.21(0.07-20.62)\end{array}$ \\
\hline Orthopnea & $\begin{array}{l}\text { Yes } \\
\text { No }\end{array}$ & $\begin{array}{l}\text { II (6.6) } \\
\text { I3 (22.0) }\end{array}$ & $\begin{array}{l}156(93.4) \\
46(78.0)\end{array}$ & $\begin{array}{l}4.01(1.68-9.54) \\
\text { Ref }\end{array}$ & $\begin{array}{l}6.63(2.94-46.76) * \\
\operatorname{Ref}\end{array}$ \\
\hline Metoprolol & $\begin{array}{l}\text { Yes } \\
\text { No }\end{array}$ & $\begin{array}{l}\text { II (23.4) } \\
\text { I3 (7.3) }\end{array}$ & $\begin{array}{l}36(76.6) \\
166(92.7)\end{array}$ & $\begin{array}{l}0.26(0.11,0.62) \\
\text { Ref }\end{array}$ & $\begin{array}{l}0.55(0.10-3.04) \\
\text { Ref }\end{array}$ \\
\hline UFH & $\begin{array}{l}\text { Yes } \\
\text { No }\end{array}$ & $\begin{array}{l}5(31.3) \\
19(9.0)\end{array}$ & $\begin{array}{l}\text { II (68.8) } \\
191(91.0)\end{array}$ & $\begin{array}{l}0.22(0.07,0.69) \\
\text { Ref }\end{array}$ & $\begin{array}{l}0.16(0.01-1.95) \\
\operatorname{Ref}\end{array}$ \\
\hline Number of medications & $\begin{array}{l}<3 \\
\geq 3\end{array}$ & $\begin{array}{l}2(2.1) \\
22(16.7)\end{array}$ & $\begin{array}{l}92(97.9) \\
110(83.3)\end{array}$ & $\begin{array}{l}\text { Ref } \\
9.20(2.11-40.16)\end{array}$ & $\begin{array}{l}\text { Ref } \\
2.16(0.14-33.29)\end{array}$ \\
\hline $\mathrm{INO}_{2}$ & $\begin{array}{l}\text { Yes } \\
\text { No }\end{array}$ & $\begin{array}{l}14(16.5) \\
10(7.1)\end{array}$ & $\begin{array}{l}7 \mid(83.5) \\
131(92.9)\end{array}$ & $\begin{array}{l}2.58(1.09-6.12) \\
\operatorname{Ref}\end{array}$ & $\begin{array}{l}9.41(1.35-65.82) * \\
\operatorname{Ref}\end{array}$ \\
\hline
\end{tabular}

Note: Ref: Reference category, *statistically significant at $p<0.05$.

Abbreviations: HTN, hypertension; IHD, ischemic heart disease; CAP, community acquired pneumonia; LVEF, left ventricular ejection fraction; UFH, unfractionated heparin; $\mathrm{INO}_{2}$, intranasal oxygen therapy; COR, crude odd ratio; $\mathrm{AOR}$, adjusted odd ratio; $\mathrm{Cl}$, confidence interval.

In this study, 71 (31.4\%) of the patients were admitted with an unknown precipitating factor. Of the defined ones, CAP was the main precipitating factor in $83(36.7 \%)$ of AHF patients. Among the ADCHF patients, noncompliance to medication $38(42.6 \%)$ was the leading precipitating factor. The overall mean LVEF of the cohort was $48.00 \pm 20.39$, while the percentage of patients with HF with reduced ejection fraction and HF with preserved ejection fraction were $83(36.7 \%)$ and $136(60.2 \%)$, respectively. On admission, $221(97.8 \%)$ of patients had NYHA class IV HF, while only $5(2.2 \%)$ of patients were admitted with NYHA class III HF (Table 1). On admission 204 (90.3\%), 194 (85.8\%), 182 (80.5\%), and 167 (73.9\%) of patients were presented with dyspnea on exertion, dyspnea at rest, peripheral edema, and orthopnea, respectively (Figure 1). 


\section{In-Hospital Management of AHF and Discharge Medications}

During hospitalization, almost all 224 (99.1\%) patients were treated with furosemide. Next to furosemide, the most commonly used agents were aspirin 83 (36.7\%), atorvastatin 79 (35\%), and spironolactone 65 (28.8\%). At discharge furosemide $185(81.9 \%)$, spironolactone 76 $(33.6 \%)$, and enalapril $55(24.3 \%)$ were the most commonly prescribed medications. Mechanical ventilation using $\mathrm{INO}_{2}$ was used in $85(37.6 \%)$ of patients (Figure 2).

\section{In-Hospital Outcomes of AHF}

Of the 226 admitted patients, $10.6 \%$ (95\% CI: 7.1-14.7) patients died in the hospital, while $72.1 \%$ (95\% CI: 66.4 77.6) of patients were discharged after symptom improvement. In addition, a total of 15\% (95\% CI: $11.0-20.9)$ of patients left against medical advice and 2.2\% (95\% CI: 0.4-4.4) patients were transferred to the higher health care facility. The median (IQR) length of hospital stay was 17 (11-21) days.

\section{Factors Associated with In-Hospital Mortality}

Bivariable binary logistic regression indicated that inhospital mortality was associated with concurrent HTN $(\mathrm{COR}=5.82 ; \quad 95 \% \quad \mathrm{CI}: \quad 2.39-11.16)$, renal disease $(\mathrm{COR}=4.45 ; 95 \% \mathrm{CI}: 1.85-10.91)$, IHD $\quad(\mathrm{COR}=12.53$; 95\% CI: 4.44-35.38), stroke $(\mathrm{COR}=5.63$; 95\% CI: 1.26 25.23), being admitted with reduced LVEF (COR=15.80; 95\% CI: 4.55-54.95), elevated serum creatinine $(\mathrm{COR}=4.01 ; 95 \% \mathrm{CI}: 1.68-9.54)$, presence of orthopnea $(\mathrm{COR}=4.01 ; 95 \% \mathrm{CI}: 1.68-9.54)$, being prescribed with $\geq 3$ medications during the hospital course $(\mathrm{COR}=9.20 ; 95 \%$ CI: 2.11-40.16), and using $\mathrm{INO}_{2}(\mathrm{COR}=2.58$; 95\% CI: 1.09-6.12). Additionally, in-hospital mortality was associated with the precipitating factors of AHF specifically $\mathrm{AF}(\mathrm{COR}=3.33$; 95\% CI: $1.03-10.78)$ and non-compliance to medical regimen $(\mathrm{COR}=3.98 ; 95 \% \mathrm{CI}: 1.30-12.18)$ in bivariable logistic regression. In the multivariable binary logistic regression precipitating factors of AHF specifically AF (AOR=9.46; 95\% CI: 1.49-60.29), concurrent IHD $(\mathrm{AOR}=8.23 ; 95 \% \mathrm{CI}: 1.15-58.89)$, being admitted with reduced LVEF $(\mathrm{AOR}=5.36 ; 95 \% \mathrm{CI}$ : 2.81-35.52), presence of orthopnea $(\mathrm{AOR}=6.63 ; 95 \% \mathrm{CI}: 2.94-46.76)$ and using $\mathrm{INO}_{2}(\mathrm{AOR}=9.41 ; 95 \% \mathrm{CI}$ : 1.35-65.82) were significantly associated with in-hospital mortality in patients with heart failure (Table 2).

\section{Discussion}

The findings of this study indicated that the majority of HAHF patients were presented with new-onset HF. In ADCHF patient's non-compliance to medication was the major precipitating factor, while IHD was the primary cause for AHF admission. In this study, CAP was the most prevalent comorbidity, and furosemide was the most frequently used medication for the treatment of patients with AHF. In agreement with previous studies, ${ }^{9,16}$ a large percentage, 60.6\% (95\% CI: 54.967.3) of patients were admitted with new-onset AHF. The mean LVEF was $48 \pm 20.39 \%$ (95\% CI: $44.89-$ $50.75)$ which was higher than that reported in other previously conducted studies. ${ }^{8,11,13,15,22}$ This might be due to the presence of a high percentage of patients with preserved LVEF (63.3\%) in this study. Like the Ugandan study, ${ }^{19}$ dyspnea on exertion (90.3\%) was the most frequent clinical finding. IHD (27\%), CRHD (19.5\%), and corpulmonale (17.7\%) were the top three causes for AHF hospital admission. This finding was confirmed by other studies where ischemia, CRHD, and corpulmonale were the leading causes for AHF related hospital admission. $^{13,14,17,21}$

Despite the majority, $31.4 \%$ of patients were admitted with an unknown precipitating factor, CAP (48.2\%) was the main precipitant factors among new-onset AHF patients, while non-compliance to the medication $(42.6 \%)$ was the leading one among ADCHF patients. In line with a previous study conducted in Ethiopia, it was revealed that pneumonia $(47.5 \%)$ and drug discontinuation $(22.5 \%)$ were the top precipitating factors. ${ }^{21}$ This finding was supported by the Turkish HF registry, which reported that non-noncompliance with treatment (34\%) was the most frequent factor associated with decompensation. ${ }^{11}$ Similarly, a study conducted in Turkey explained that infection (29.3\%) and non-compliance with medication $(23.8 \%)$ were the frequent precipitating factors of $\mathrm{AHF}^{8}$ A study in Uganda also reported that among patients with a prior admission for HF medication noncompliance $(31.7 \%)$ was the leading precipitating factor for decompensation. ${ }^{9}$

In the current study, the in-hospital mortality of AHF patients was $10.6 \%$ (95\% CI: 7.1-14.7). This is in agreement with previous studies conducted in the OFICA study $(8.2 \%),{ }^{10}$ South Africa $(8.4 \%),{ }^{17}$ and Turkey $(7.6 \%){ }^{8}$ However, this finding was higher than previous studies reported in the Italian HF registry $(6.4 \%),{ }^{15}$ Japanese Cardiac Registry of Heart Failure (5.6\%), ${ }^{27}$ Turkish HF 
registry $(3.4 \%),{ }^{11}$ Gulf acute heart failure registry $(6.3 \%){ }^{7}$ Korean HF registry $(4.8 \%){ }^{4}$ and China HF registry $(4.4 \%)^{6}$ This might be due to the existence of nonadherence to the medical regimens as one of the leading precipitating factors for AHF admission in the present study. Besides, poor economic status and quality of health care in developing countries might contribute to the increased mortality in the current study.

Of the survived patients, $72.1 \%$ (95\% CI: 66.4-77.6) of patients were discharged with symptom improvement, which was comparable with the value reported in Uganda $(75.2 \%)^{9}$ and the ALARM-HF survey $(74.13 \%) .^{28}$ However, it was lower than the finding reported by Gulf acute heart failure registry $(89 \%){ }^{7}$ In the present study, $15 \%$ (95\% CI: $10.0-19.6)$ of patients left against medical advice which was higher than that reported in Uganda (5.1\%). ${ }^{9}$ In this study, 2.2\% $(95 \%$ CI: $0.4-4.4$ ) of patients were transferred to a higher level of care, which was comparative with Gulf acute heart failure registry $(1.8 \%)^{7}$ and the Ugandan study $(1.5 \%){ }^{9}$

In the current study, AHF patients admitted with reduced LVEF were 5.36 times more likely to die in the hospital than those who were admitted with preserved LVEF (AOR= 5.36; 95\% CI: 2.81-35.52). In line with this, the Kyoto Congestive Heart Failure Registry reported that the in-hospital mortality rate was higher in the HFrEF than in the HFpEF groups. ${ }^{29}$ In line with this, the Ugandan study revealed that reduced LVEF was associated with high risk of in-hospital mortality. ${ }^{9}$ Similarly, the Organized Program to Initiate Lifesaving Treatment in Hospitalized Patients with Heart Failure registry also explained that left ventricular systolic dysfunction as a predictor of in-hospital mortality. ${ }^{30}$

AHF patients with concurrent IHD are 8.23 times at risk of in-hospital mortality than their counterparts $(\mathrm{AOR}=8.23$; 95\% CI; 1.15-58.89). This is comparable with the study done in the China HF registry. ${ }^{6}$ The finding of this study showed that AF is another associated factor of in-hospital mortality in AHF patients (AOR=9.46; 95\% CI: 1.4960.29). This was supported by the EuroHeart Failure Survey, which reported that AF was an independent predictor of in-hospital mortality in HAHF patients. ${ }^{31}$ Additionally, in the present study, AHF patients who were using intranasal oxygen therapy $\left(\mathrm{INO}_{2}\right)$ were 9.41 times more likely to die in the hospital than those who were not administered with $\mathrm{INO}_{2}$. The finding is in agreement with current reviews on the role of oxygen therapy in AHF patients $^{32}$ and previous clinical trials. ${ }^{33}$ This might be due to the increased production of reactive oxygen species and the related oxidative stress and by the reductions in coronary blood flow and myocardial oxygen consumption resulting from hyperoxia-induced vasoconstriction in the cerebral, coronary, and systemic vasculature. ${ }^{32}$ On the contrast, studies have shown that positive airway pressure ventilation could improve the prognosis in patients with $\mathrm{CHF}$ and sleep apnea. $^{34-37}$

Despite the bivariable logistic regression demonstrated that elevated serum creatinine and renal disease were associated with in-hospital mortality, the multiple regression showed that elevated serum creatinine and renal disease were not significantly associated with in-hospital mortality. In contrast to this finding, previous studies ${ }^{10,15,16,30}$ reported that elevated serum creatinine and renal dysfunction were associated with increased risk of in-hospital mortality. This might be attributed to a large number of AHF patients included in those studies.

Decreasing in-hospital mortality of HAHF is the principal goal of therapy in the management of HF. However, the present study revealed that there was high in-hospital mortality of HAHF patients. This could be rather than the individual patient clinical characteristics, in-hospital mortality of patients might be affected by organizational and patient care process. This suggests that public health policymakers should put interventions or strategies that could improve the survival of HAHF patients. Thus, to investigate a variety of factors which might affect the in-hospital mortality of AHF researchers should do further research by considering both organizational and patient care processes in a large population with multicenter health facilities.

\section{Strength and Limitation of the Study}

In addition to its prospective nature, this study evaluates the in-hospital outcomes of HAHF patients using different parameters; in-hospital mortality, discharged after symptom improvement, went against medical advice and transferred to higher level of care. Despite these strengths, the study also had its own limitations: since the study was conducted in a single centered health facility and relatively inadequate sample size generalizability of the results is limited. Besides, estimated glomerular filtration rate (eGFR), which is a good biomarker for renal dysfunction than serum creatinine level, was not considered. 


\section{Conclusion}

In the current study, the in-hospital mortality of the AHF patients was higher than those reported in previous studies conducted globally. Reduced left ventricular ejection fraction, atrial fibrillation, ischemic heart disease, orthopnea, and intranasal oxygen therapy were associated with inhospital mortality of AHF patients. Therefore, specific preventative and therapeutic strategies focusing on HAHF patients might need to be considered for HF patients in the study area.

\section{Abbreviations}

ADCHF, acute decompensated heart failure; AF, atrial fibrillation; AHF, acute heart failure; AOR, adjusted odds ratio; CI, confidence interval; COR, crude odd ratio; CRHD, chronic rheumatic heart disease; DCM, dilated cardiomyopathy; DVHD, degenerative valvular heart disease; HAHF, hospitalized acute heart failure; HF, heart failure; HTN, hypertension; IHD, ischemic heart disease; $\mathrm{INO}_{2}$, intranasal oxygen therapy; IQR, interquartile range; LVEF, left ventricular ejection fraction; NYHA, New York Heart Association; $\mathrm{SD}$, standard deviation; UFH, unfractionated heparin.

\section{Data Sharing Statement}

The datasets used and analyzed during the current study are available from the corresponding author on reasonable request.

\section{Ethical Approval}

The study was approved by the Research and Ethical Review Committee of School of Pharmacy, College of Medicine and Health Sciences, University of Gondar. The study was also done per the declaration of Helsinki.

\section{Acknowledgments}

The authors acknowledge the School of Pharmacy, University of Gondar, all staff members of the medical ward for their cooperation during conducting this study, and the study participants for their willingness to be involved in the research project.

\section{Author Contributions}

All authors made substantial contributions to conceptualization and design, data acquisition, data analysis and interpretation, took part in drafting of the initial manuscript and revising it critically, gave final approval of the version to be published, agreed to submit to the current journal, and agreed to be accountable for all aspects of the work.

\section{Funding}

The authors received no specific funding for this work.

\section{Disclosure}

The authors declare that they have no conflicts of interest for this work.

\section{References}

1. Yancy CW, Jessup M, Bozkurt B, et al. 2013 ACCF/AHA guideline for the management of heart failure: executive summary: a report of the American College of Cardiology Foundation/American Heart Association Task Force on practice guidelines. Circulation. 2013;128(16):1810-1852. doi:10.1161/CIR.0b013e31829e8807

2. Ponikowski P, Voors AA, Anker SD, et al. 2016 ESC guidelines for the diagnosis and treatment of acute and chronic heart failure: the task force for the diagnosis and treatment of acute and chronic heart failure of the European Society of Cardiology (ESC)developed with the special contribution of the Heart Failure Association (HFA) of the ESC. Eur Heart J. 2016;37(27):2129-2200.

3. Kapoor JR, Kapoor R, Ju C, et al. Precipitating clinical factors, heart failure characterization, and outcomes in patients hospitalized with heart failure with reduced, borderline, and preserved ejection fraction. JACC Heart Fail. 2016;4(6):464-472. doi:10.1016/j. jchf.2016.02.017

4. Lee SE, Lee HY, Cho HJ, et al. Clinical characteristics and outcome of acute heart failure in Korea: results from the Korean Acute Heart Failure Registry (KorAHF). Korean Circ J. 2017;47(3):341-353. doi:10.4070/kcj.2016.0419

5. Fonarow GC, Abraham WT, Albert NM, et al. Factors identified as precipitating hospital admissions for heart failure and clinical outcomes: findings from OPTIMIZE-HF. Arch Intern Med. 2008;168 (8):847-854. doi:10.1001/archinte.168.8.847

6. Zhang Y, Zhang J, Butler J, et al. Contemporary epidemiology, management, and outcomes of patients hospitalized for heart failure in China: results from the China Heart Failure (China-HF) registry. $J$ Card Fail. 2017;23(12):868-875. doi:10.1016/j.cardfail.20 17.09.014

7. Sulaiman K, Panduranga P, Al-Zakwani I, et al. Clinical characteristics, management, and outcomes of acute heart failure patients: observations from the Gulf acute heart failure registry (Gulf CARE). Eur J Heart Fail. 2015;17(4):374-384. doi:10.1002/ejhf.245

8. Sinan ÜY, Ekmekçi A, Özbay B, et al. The real-life data of hospitalized patients with heart failure: on behalf of the Journey HF-TR study investigators. Anatol J Cardiol. 2019;21(1):25-30.

9. Okello S, Rogers O, Byamugisha A, Rwebembera J, Buda AJ. Characteristics of acute heart failure hospitalizations in a general medical ward in Southwestern Uganda. Int J Cardiol. 2014;176 (3):1233-1234. doi:10.1016/j.ijcard.2014.07.212

10. Logeart D, Isnard R, Resche-Rigon M, et al. Current aspects of the spectrum of acute heart failure syndromes in a real-life setting: the OFICA study. Eur J Heart Fail. 2013;15(4):465-476.

11. Eren M, Zoghi M, Tuncer M, et al. Turkish registry for diagnosis and treatment of acute heart failure: TAKTIK study. Turk Kardiyol Dern Ars. 2016;44(8):637-646.

12. Zeru MA. Assessment of major causes of heart failure and its pharmacologic management among patients at Felege Hiwot referral hospital in Bahir Dar, Ethiopia. J Public Health Epidemiol. 2018;10 (9):326-331. doi:10.5897/JPHE2018.1046 
13. Nkoke C, Jingi AM, Aminde LN, et al. Heart failure in a semi-urban setting in Cameroon: clinical characteristics, etiologies, treatment and outcome. J Xiangya Med. 2019;4:11. doi:10.21037/jxym.2019.02.01

14. Asfaw E. Five years clinical characteristics and in hospital outcome of acute heart failure at tertiary care hospital in Ethiopia. Ethiop Med J. 2020;58.

15. Oliva F, Mortara A, Cacciatore G, et al. Acute heart failure patient profiles, management and in-hospital outcome: results of the Italian registry on heart failure outcome. Eur J Heart Fail. 2012;14 (11):1208-1217. doi:10.1093/eurjhf/hfs 117

16. Spinar J, Parenica J, Vitovec J, et al. Baseline characteristics and hospital mortality in the Acute Heart Failure Database (AHEAD) main registry. Crit Care. 2011;15(6):R291. doi:10.1186/cc10584

17. Szymanski P, Badri M, Mayosi B. Clinical characteristics and causes of heart failure, adherence to treatment guidelines, and mortality of patients with acute heart failure: experience at Groote Schuur Hospital, Cape Town, South Africa. S Afr Med J. 2018;108 (2):94-98. doi:10.7196/SAMJ.2018.v108i2.12519

18. Panduranga P, Sulaiman K, Al-Zakwani I, et al. Demographics, clinical characteristics, management, and outcomes of acute heart failure patients: observations from the Oman acute heart failure registry. Oman Med J. 2016;31(3):188-195. doi:10.5001/ omj.2016.37

19. Boombhi J. Clinical pattern and outcome of acute heart failure at the yaounde central hospital. Open Access Lib J. 2017;4(03):1.

20. Wajner A, Zuchinali P, Olsen V, Polanczyk CA, Rohde LE. Causes and predictors of in-hospital mortality in patients admitted with or for heart failure at a tertiary hospital in Brazil. Arq Bras Cardiol. 2017;109(4):321-330.

21. Tirfe M, Nedi T, Mekonnen D, Berha AB. Treatment outcome and its predictors among patients of acute heart failure at a tertiary care hospital in Ethiopia: a prospective observational study. $B M C$ Cardiovasc Disord. 2020;20(1):16. doi:10.1186/s12872-019-01318-x

22. Damasceno A, Mayosi BM, Sani M, et al. The causes, treatment, and outcome of acute heart failure in 1006 Africans from 9 countries: results of the sub-Saharan Africa survey of heart failure. Arch Intern Med. 2012;172(18):1386-1394. doi:10.1001/archinternmed.20 12.3310

23. Medicine I, Press NA. Cardiovascular Disability: Updating the Social Security Listings. National Academies Press; 2010.

24. Bekele F, Fekadu G, Dugassa D, Bekele K. Non-compliance and its associated factors among hypertensive patients taking anti-hypertensive treatment visiting Gimbi general hospital Western Ethiopia: cross-sectional study. J Pharm Pharm. 2019;6(2):65-71.

25. Sika-Paotonu D, Beaton A, Raghu A, Steer A, Carapetis J. Acute rheumatic fever and rheumatic heart disease. S Pyogenes. 2017.

26. World Health Organiztion. Hemoglobin Concentrations for the Diagnosis of Anemia and Assessment of Severity. Vitamin and Mineral Nutrition Information System. Geneva: 2011 World Health Organization (WHO/NMH/NHD/MNM/111); 2017.
27. Hamaguchi S, Kinugawa S, Tsuchihashi-Makaya M, et al. Characteristics, management, and outcomes for patients during hospitalization due to worsening heart failure-a report from the Japanese Cardiac Registry of Heart Failure in Cardiology (JCARE-CARD). J Cardiol. 2013;62(2):95-101. doi:10.1016/j.jjcc.2013.03.009

28. Mebazaa A, Parissis J, Porcher R, et al. Short-term survival by treatment among patients hospitalized with acute heart failure: the global ALARM-HF registry using propensity scoring methods. Intensive Care Med. 2011;37(2):290-301. doi:10.1007/s00134-0102073-4

29. Yaku H, Ozasa N, Morimoto T, et al. Demographics, management, and in-hospital outcome of hospitalized acute heart failure syndrome patients in contemporary real clinical practice in Japan- observations from the prospective, multicenter Kyoto Congestive Heart Failure (KCHF) registry. Circ J. 2018;82(11):2811-2819. doi:10.1253/circj. CJ-17-1386

30. Abraham WT, Fonarow GC, Albert NM, et al. Predictors of in-hospital mortality in patients hospitalized for heart failure: insights from the Organized Program to Initiate Lifesaving Treatment in Hospitalized Patients with Heart Failure (OPTIMIZE-HF). J Am Coll Cardiol. 2008;52(5):347-356. doi:10.1016/j.jacc.2008.04.028

31. Rivero-Ayerza M, Scholte Op Reimer W, Lenzen M, et al. New-onset atrial fibrillation is an independent predictor of in-hospital mortality in hospitalized heart failure patients: results of the EuroHeart failure survey. Eur Heart J. 2008;29(13):1618-1624. doi:10.1093/eurheartj/ ehn 217

32. Sepehrvand N, Ezekowitz JA. Oxygen therapy in patients with acute heart failure: friend or foe? JACC Heart Fail. 2016;4(10):783-790.

33. Park JH, Balmain S, Berry C, Morton JJ, McMurray JJ. Potentially detrimental cardiovascular effects of oxygen in patients with chronic left ventricular systolic dysfunction. Heart. 2010;96(7):533-538. doi:10.1136/hrt.2009.175257

34. Jilek C, Krenn M, Sebah D, et al. Prognostic impact of sleep disordered breathing and its treatment in heart failure: an observational study. Eur J Heart Fail. 2011;13(1):68-75. doi:10.1093/eurjhf/ hfq183

35. Damy T, Margarit L, Noroc A, et al. Prognostic impact of sleep-disordered breathing and its treatment with nocturnal ventilation for chronic heart failure. Eur $J$ Heart Fail. 2012;14 (9):1009-1019. doi:10.1093/eurjhf/hfs085

36. Kasai T, Narui K, Dohi T, et al. Prognosis of patients with heart failure and obstructive sleep apnea treated with continuous positive airway pressure. Chest. 2008;133(3):690-696. doi:10.1378/chest.071901

37. Bradley TD, Logan AG, Kimoff RJ, et al. Continuous positive airway pressure for central sleep apnea and heart failure. $N$ Engl J Med. 2005;353(19):2025-2033. doi:10.1056/NEJMoa051001
Vascular Health and Risk Management

\section{Publish your work in this journal}

Vascular Health and Risk Management is an international, peerreviewed journal of therapeutics and risk management, focusing on concise rapid reporting of clinical studies on the processes involved in the maintenance of vascular health; the monitoring, prevention and treatment of vascular disease and its sequelae; and the involvement of metabolic disorders, particularly diabetes. This journal is indexed on PubMed Central and MedLine. The manuscript management system is completely online and includes a very quick and fair peerreview system, which is all easy to use. Visit http://www.dovepress. com/testimonials.php to read real quotes from published authors. 